\title{
El reflejo léxico de las posturas políticas: vaivenes políticos de un prelado de sangre regia
}

\author{
The lexical reflection of the political positions: political \\ fluctuations of a prelate with royal blood
}

\author{
Óscar Villarroel González ${ }^{*}$
}

\begin{abstract}
RESUMEN ABSTRACT
El estudio del léxico sirve como fuente de aproximación a los cambios de postura política adoptados por un prelado del siglo

XV como fue Pedro de Castilla, así como a la forma en que se apreció y reflejó su actitud.

The study of the lexicon is a source of approximation to the changes of political position adopted by a prelate of the 15th century, as well as to the form in which his attitude was appreciated and reflected in the cronicles and documentation.
\end{abstract}

\section{PALABRAS CLAVE}

Lexicografía, Castilla, Pedro de Castilla, postura política.

\section{KEY WORDS}

Lexicography, Castile, Peter of Castile, political position.

\section{INTRODUCCIÓN Y METODOLOGÍA}

A lo largo del periodo bajomedieval se produjeron una larga serie de conflictos políticos en el seno de la Corona de Castilla, en los que los eclesiásticos pertenecientes a la alta jerarquía castellana participaron, como si se tratase de un miembro más de la nobleza. Este hecho, que ya fue destacado por la historiografía ${ }^{1}$, tuvo

* Universidad Complutense de Madrid. El presente trabajo se enmarca dentro del proyecto de investigación Las relaciones de conflicto en sus prácticas representativas. (La Corona de Castilla en su contexto europeo, siglos XII-XV), (HUM2006-05233), dirigido por José Manuel Nieto Soria.

Siglas utilizadas: A C (Archivo Capitular), A S V (Archivio Segreto Vaticano), Reg. Vat (Registra Vaticana), Reg. Avin (Registra Avenionensia), Cam. Ap. (Camera apostolica), y Obl. Comm (Obligationes pro communibus servitiis).

1 En el contexto de la Castilla trastámara fue analizado por NIETO SORIA, J.M., Iglesia y génesis del Estado moderno en Castilla (1369-1474), Madrid, 1993; yo mismo analicé en mi tesis doctoral el desa- 
como consecuencia que muchos prelados y prebendados participasen, activamente incluso, en los enfrentamientos y, como analicé recientemente, en los diversos bandos o partidos que se iban formando en la corte al calor de los mencionados conflictos?

Esta presencia y participación se desarrolló en una completa gama de posibilidades. Como ya indicó hace años Nieto Soria, la posición de los eclesiásticos variaba entre la constante oposición al rey y el servicio continuo, pasando por un amplio repertorio de cambios de opinión y bando político, siempre al albur de su propio interés ${ }^{3}$. Así, el beneficio particular se manifestaba como la principal fuerza de acción política, y en la causa de los movimientos y la participación de muchos eclesiásticos.

En este trabajo se pretende mostrar a través de la figura de un prelado del siglo xv, Pedro de Castilla, cómo, cuándo y por qué se desarrollaron esos cambios de la posición política. Este prelado puede ser un caso paradigmático puesto que, pese a tener ascendencia real, no tenía una familia noble tras él, con lo que sus movimientos y acciones políticas dependían sólo de su propia intención. Así, veremos cómo su capacidad de intervenir y actuar en la política castellana a lo largo de los reinados de Juan II y Enrique IV dependió sólo de su propia capacidad, y cómo la posición que tomase en los conflictos dependió sólo de su iniciativa y de lo que considerase en cada momento que repercutía en su beneficio. Y, evidentemente, apreciaremos cómo fueron vistas por la Monarquía las diferentes posiciones políticas que adoptase el prelado, así como las medidas que tomase por ello.

Sin ser uno de los principales eclesiásticos del reino, Pedro de Castilla desarrolló una extensa carrera. Como veremos, en ello tuvo una especial relevancia sus actuaciones políticas, así como los apoyos que desde la familia real podía recibir. Al hilo del desarrollo de la misma iremos haciendo un análisis de cómo se refieren la documentación y las crónicas al mismo, realizando un análisis lexicográfico que nos permita acceder a cómo fue vista su participación política.

La forma de acceder a ese posicionamiento del prelado será por medio del análisis léxico de la documentación conservada que se refiere a él, junto al de los propios hechos que protagonizaba. Este tipo de análisis se ha mostrado en los últimos años como una herramienta mixta entre la lexicografía y la historia para acceder a las voluntades y las percepciones de las cuestiones políticas que se tenían en un momento concreto ${ }^{4}$. Hasta ahora ha sido muy poco utilizado por la

rrollo de esta serie de participaciones: VILLARROEL GONZÁLEZ, O., Las relaciones Monarquía-Iglesia en época de Juan II de Castilla (1406-1454), Universidad Complutense de Madrid, 2006, pp. 667-770, disponible edición digital de la UCM, Madrid, 2007.

2 VILLARROEL GONZÁLEZ, O., «Servir al rey en las ligas nobiliarias: los eclesiásticos en las confederaciones políticas», Anuario de Estudios Medievales, 36/2 (2006), pp. 751-781.

3 NIETO SORIA, J.M., Iglesia y génesis..., p. 263.

4 Algunas consideraciones sobre la lexicometría y la historia: GENET, J.P. «Le médieviste, la naissance du discours politique et la statistique lexicale: quelques problemes", en L'Ecrit dans la societe medievale. Divers aspects de sa pratique du xı au xve siècle, París, 1991, pp. 289-298. 
historiografía hispana ${ }^{5}$, pero se demuestra de una gran utilidad para desentrañar aspectos ciertamente relevantes de la realidad política, como eran la percepción de la realidad que se tenía desde una posición específica.

Para el caso específico de la toma de posición política por parte de un personaje concreto tenemos el handicap de contar, habitualmente, sólo con fuentes parciales. Sin embargo, la aceptación de los resultados que el análisis de este tipo arroje debe basarse en varias premisas. Primero, sin lugar a dudas hay que aceptar que la visión puede ser «parcial», en el sentido de que nos muestra cómo veía las cosas una de las partes enfrentadas; en segundo lugar, y por tanto, sólo la confrontación de tales resultados con otras fuentes puede evitar la subjetividad. El reinado de Juan II de Castilla, en este sentido, tiene una cierta ventaja sobre otros momentos de la historiografía castellana, puesto que nos encontramos con una gran variedad de fuentes, y con orientaciones ideológicas ciertamente distintas.

En lo que atañe a este trabajo concreto, hemos de partir de las fuentes disponibles, fundamentalmente las crónicas y la documentación regia. Así, si hemos de analizar las relaciones entre un prelado rebelde y la Monarquía, no cabe duda que la documentación regia puede resultar parcial. Esto se verá solucionado por medio de la utilización de fuentes de origen eclesiástico y, sobre todo, de las crónicas. En este sentido las crónicas sirven de ayuda, puesto que las que se conservan tienen ciertos matices en cuanto a su orientación ideológica que nos permiten, en algunos casos, equilibrar la balanza ${ }^{6}$. De esta forma veremos cómo era vista la toma de postura del prelado desde el poder regio, e intentaremos desentrañar cómo lo era desde otros ámbitos.

Las crónicas del reinado de Juan II de Castilla suponen todo un reto a la hora de acceder a sus contenidos, así como a sus orígenes y momentos de redacción?. La cronística de este reinado ha sido calificada como el momento culminante en la evolución de las crónicas a lo largo de la Baja Edad Media en cuanto al reflejo del momento histórico ${ }^{8}$. Al excelente trabajo, ya mencionado, de Gómez Redondo nos remitiremos de forma constante a la hora de la interpretación de los datos, se-

\footnotetext{
${ }^{5}$ Para la historia castellana, desde la historiografía hispanista, fue casi pionero François FORONDA en su tesis doctoral (La privanza ou le régime de la faveur. Autorité monarchique et puissance aristocratique en Castille (XIle-XVe siècle, tesis doctoral leída en la Universidad Paris I Panthéon-Sorbonne, 2003, dirigida por Claude Gauvard y J.M. Nieto Soria) y su trabajo monográfico «S'emparer du roi. Un rituel d'integration politique dans la Castille Trastamare", en FORONDA., F., GENET, J.P., y NIETO SORIA, J.M., (dirs.), Coups d'État à la fin du Moyen Âge? Aux fondements du pouvoir politique en Europe occidentale, Madrid, 2005, pp. 213-329; posteriormente se ha realizado algún otro trabajo concreto, como el análisis del Primer Seguro de Tordesillas realizado por Ana Isabel CARRASCO MANCHADO («Léxico político en el Seguro de Tordesillas», en F. FORONDA y A.I. CARRASCO MANCHADO (dirs.), Du contrat d'alliance au contrat politique Cultures et sociétés politiques dans la péninsule Ibérique de la fin du Moyen-Âge, Toulouse, 2007, pp. 85-137.

6 Sobre la cronística del reinado de Juan II véase el análisis realizado por GÓMEZ REDONDO, F., Historia de la prosa medieval castellana, vol. III Los orígenes del humanismo. Los reinados de Enrique III y Juan II, Madrid, 2002, pp. 2.207-2.332. 2.208

7 Alguna de ellas ha sido calificada como «la más compleja de las crónicas del siglo XV», ibídem, p.

8 Ibídem, p. 2.207.
} 
gún la autoría, el momento y la intención de la redacción de las distintas obras. Básicamente, atenderemos a las siguientes crónicas y/o fragmentos: la Crónica de Juan II, de Alvar García de Santa María; la Crónica del halconero de Juan II, de Pedro Carrillo de Huete; la obra cronística de Lope de Barrientos, la de Fernán Pérez de Guzmán, la Crónica de Álvaro de Luna y la llamada Abreviación del halconero.

La Crónica de Juan II de Castilla redactada por García de Santa María nos ha llegado de forma fragmentada. En concreto para este trabajo nos atañe la segunda parte, que a su vez fue revisada y/o enmendada por Fernán Díaz de Toledo?. Ambos fueron servidores regios, por lo que podemos ver en su obra una clara tendencia a ensalzar el poder regio si bien en esta segunda parte Díaz de Toledo posiblemente influyó por orden del valido para mostrar más claramente su figura y su poder $^{10}$.

En cuanto a la Crónica del halconero'11, podemos ver en él una clara visión regia, dado que nos muestra al rey como el centro de la misma, siendo una autoridad sin contestación posible en el reino, rodeado de símbolos de autoridad ${ }^{12}$. Así, los datos que nos transmita pueden tener una notable relevancia al respecto. La obra de Barrientos puede tener un valor semejante, dada su notable cercanía y su inquebrantable fidelidad Juan II, al que muestra también rodeado de símbolos de autoridad ${ }^{13}$.

Fernán Pérez de Guzmán fue considerado como el principal cronista de Juan II de Castilla durante mucho tiempo. El hecho de que en la obra de Galíndez se le mencionase como tal hizo que la crónica de éste se mencionase como suya durante mucho tiempo. Juan de Mata Carriazo opinó lo contrario. Recientemente Fernando Gómez Redondo ha mostrado cómo Carriazo tenía razón, pero sólo en parte, pudiendo considerar autor a Pérez de Guzmán de una parte del texto de Galíndez (aunque fuese revisado e interpolado por éste) ${ }^{14}$.

Pero además, podemos considerarle también como autor del conjunto cronístico publicado por Juan de Mata Carriazo como Refundición de la crónica del

9 Ibídem, p. 2.232.

10 Ibídem, pp. 2.232-2.234. A lo largo de todo el trabajo se citará por medio de la edición de Documentos Inéditos para la Historia de España, XCIX y C, Madrid, 1891.

11 CARRILLO DE HUETE, P., Crónica del halconero de Juan Il de Castilla, ed. J. de M. Carriazo y Arroquia, Madrid, 1946. Consideramos perteneciente a este autor el material publicado bajo ese nombre por Juan de Mata Carriazo en 1946, pero solamente hasta 1441, momento en que tuvo que dejar la Corte. Sigo, así, las conclusiones de GÓMEZ REDONDO, F., Historia de la prosa medieval..., II, pp. 2.273. Lexicografía consultada por medio de Corde: Real Academia Española: Banco de datos (CORDE) [en línea]. Corpus diacrónico del español. <http://www.rae.es> [21 de junio de 2007]

12 Ibídem, pp. 2.271 y 2.276-2.277.

13 Aquí se considerará como la Refundición del obispo conquense el texto publicado por Juan de Mata Carriazo en 1946 como parte integrante de la Crónica del halconero de Juan II, en concreto desde el año 1441. Lexicografía consultada por medio de Corde: Real Academia Española: Banco de datos (CORDE) [en línea]. Corpus diacrónico del español. <http://www.rae.es> [21 de junio de 2007]

${ }_{14}$ GÓMEZ REDONDO, F., Historia de la prosa medieval..., II, pp. 2243. El texto se ha consultado y revisado por la antigua edición de C. Rosell: GALÍNDEZ DE CARVAJAL, L., Crónica de Juan I/ de Castilla, Madrid, 1877, vol. II de sus Crónicas de los reyes de Castilla. 
halconero ${ }^{15}$, que él asignaba a Lope de Barrientos ${ }^{16}$. Este texto, el más elaborado, tiene una notable carga de la propia posición política que el cronista tenía, lo que también puede ser muy útil a la hora de interpretar los datos que aporte sobre el personaje en estudio ${ }^{17}$. Por último, también se utilizará la llamada Abreviación del halconero ${ }^{18}$, pese a que es una obra posterior, que refunde y abrevia diversas obras cronísticas (Pérez de Guzmán, Carrillo, Barrientos...).

Como vemos, las crónicas son variadas tanto en lo que se refiere a su autoría como a la propia visión que éstos imprimieron a sus obras. Esto nos permitirá tener una visión más amplia de cómo se vio y presentó la posición y actitud de Pedro de Castilla, lo que nos permitirá un análisis más certero y profundo de la actividad del personaje.

\section{ORÍGENES PERSONALES Y DE LA CARRERA ECLESIÁSTICA DE PEDRO DE CASTILLA}

Como ya demostré anteriormente, casi sin duda Pedro de Castilla era hijo de Juan, hijo de Pedro I de Castilla y Juana de Castro ${ }^{19}$. De este modo, estaba relacionado de forma lejana con la casa reinante en Castilla. Este parentesco no habría tenido ninguna relevancia si no hubiese sido por el matrimonio de Catalina de Lancáster con Enrique III. Gracias a éste, y al Tratado de Bayona en que se acordó, los hijos de Pedro I ganaron la libertad y un valedor en la Corte, puesto que la reina Catalina estaba dispuesta a proteger y beneficiar en lo posible a sus tíos y primos, hijos y nietos de Pedro I. En el caso de Juan de Castilla y Castro, tal cláusula del Tratado de Bayona no tuvo mucha importancia, puesto que aparentemente siguió preso en el castillo de Soria hasta su muerte ${ }^{20}$. Pero sí la tendría para su hijo Pedro, que contaría con el apoyo de su prima la reina Catalina.

A este respecto no cabe tener en cuenta lo que nos transmite la historiografía genealógica desarrollada por los descendientes de Pedro de Castilla, puesto que la dramatización y la tergiversación total o parcial de los hechos es constante (al buscar unos claros objetivos: elevar la categoría y dignidad de la familia, así como su origen). Pese a ello, sí que se puede cotejar algunos hechos con la realidad,

15 Refundición de la crónica del halconero, ed. J. de M. Carriazo y Arroquia, Madrid, 1946. Lexicografía consultada por medio de Corde: Real Academia Española: Banco de datos (CORDE) [en línea] Corpus diacrónico del español. <http://www.rae.es> [21 de junio de 2007]

16 Con ello, sigo también a Gómez Redondo: Historia de la prosa medieval..., II, p. 2322.

17 Ibídem, p. 2305.

18 Biblioteca de Santa Cruz, ms. 434, editada por LARKIN, J.B., Text and Concordances of the Abreviación del Halconero, MS. 434, Bib. Univ. de Santa Cruz, Madison, 1989. Lexicografía consultada por medio de Corde: Real Academia Española: Banco de datos (CORDE) [en línea]. Corpus diacrónico del español. <http://www.rae.es> [21 de junio de 2007]

19 Véase al respecto: VILLARROEL GONZÁLEZ, O., «Pedro de Castilla (1394-1461): un obispo de Osma y sus relaciones con la Monarquía», Celtiberia, 95 (2001), pp. $133-162$.

20 Ibídem, p. 136-137. No fue el único, como se sabe, hasta 1435 no fue liberado Diego, otro hijo del rey Pedro I. 
pues, como en las leyendas, bajo la épica genealógica se esconde una base auténtica. Así, si podemos suponer que la reina Catalina jugó un importante papel en que Pedro no estuviese preso como su padre, no podemos afirmar fehacientemente que ella evitase la prisión por su intercesión ante el rey ${ }^{21}$. Del mismo modo, tampoco podemos tomar por cierta la mención a la filiación de su madre con el alcaide de la fortaleza soriana, siendo más probable que el abuelo materno de Pedro de Castilla fuese simplemente el tenente del alcaide ${ }^{22}$.

Sin embargo, sí sabemos que la reina Catalina jugó un relevante papel en los primeros momentos de la carrera eclesiástica de Pedro de Castilla. Así, el 20 de febrero de 1412 Benedicto XIII le concedía la escolastría de Zamora a petición de la reina ${ }^{23}$. Sin embargo, no fue el primer beneficio de cierta relevancia que recibía Pedro de Castilla, puesto que dos años antes, el 24 de marzo de 1410 Benedicto XIII ya le había entregado la maestrescolía de Orense, sin que conste la intervención regia ${ }^{24}$. Y dos años después recibió el arcedianato de Cuenca con el canonicato conquense anexo ${ }^{25}$. Así en 1414 el joven Pedro de Castilla ${ }^{26}$ contaba ya con la maestrescolía de Orense y la de Zamora y parecía tener un prometedor futuro gracias al apoyo de la reina regente.

La muerte de Catalina le dejó, sin duda, sin su principal valedor. El brillante futuro se vería frenado. Eso, evidentemente, no significó que se detuviese, dado que los puestos que ya ostentaba le daban la capacidad para conseguir otros beneficios menores que, en su acumulación, le podían reportar al menos una amplia retribución (lo que en esos momentos parecía uno de sus principales intereses). Efectivamente en los años siguientes tenemos constancia de todo ello. Así, en noviembre de 1418 arrendaba a Pedro Fernández (maestrescuela de Cuenca) las rentas del arcedianato de Alarcón ${ }^{27}$. Tan sólo dos meses después, en enero de 1419, sabemos que era posesor de diversas raciones en San Martín de Lara, San Nicolás de Almazán, San Miguel de Huete, y otros en Vellisca y Barajas (ambos lugares de Huete), y que los arrendaba a Diego López Belcayre por un total de 45 florines al año y durante un periodo de tres años ${ }^{28}$.

21 Empero, así parecen indicarlo: GONZÁLEZ DE FAUVE, M.E., LAS HERAS I.J., y DE FORTEZA, P., «Los cargos eclesiásticos y religiosos como estrategia de recuperación del poder de los descendientes de Pedro 1 de Castilla», En la España Medieval, 24 (2001), pp. 239-257, p. 242.

22 Véanse al respecto las apreciaciones que ya hice anteriormente: VILLARROEL GONZÁLEZ, O., «Pedro de Castilla...», pp. 135-136. Cfr. con GONZÁLEZ DE FAUVE, M.E., LAS HERAS I.J., y DE FORTEZA, P., «Los cargos eclesiásticos...», p. 242. No así cuando hablan de la legitimidad del matrimonio de Pedro I y Juana de Castro, así como de la interpolación del testamento: ibídem, p. 241, cfr. con lo que dije anteriormente: VILLARROEL GONZÁLEZ, O., «Pedro de Castilla...», p. 134-135.

23 BELTRÁN DE HEREDIA, V., Bulario de la Universidad de Salamanca (1219-1549), Salamanca, 1966 (existe reimpresión facsimilar (edición bajo demanda) disponible en la Universidad de Salamanca), II, doc. 459 , p. 46.

24 Ibídem, II, doc. 426, p. 13.

25 BELTRÁN DE HEREDIA, V., Bulario de la Universidad..., II, doc. 490, p. 66.

${ }^{26}$ Por entonces tenía 20 años, sobre su nacimiento, véase: VILLARROEL GONZÁLEZ, O., «Pedro de Castilla...», p. 137.

27 A C Cuenca, Secretaría, Actas capitulares, Libro III, f. 23v.

28 Ibídem, f. 33r. 
A lo largo de todos esos años podemos suponerle en la universidad salmantina, donde estaba puesto su interés (de ahí la necesidad de obtener las rentas). En este sentido la historiografía de los Castilla indicaba que la reina se encargó de que estuviese estudiando en Salamanca; pero cabe preguntarse por la realidad de tal aseveración. Lo cierto es que Pedro de Castilla no estuvo en Cuenca, pese a haber recibido el arcedianato, hasta octubre de 1418, es decir, cuatro años después de que recibiese esa prebenda. En concreto el día 7 de octubre prestaba juramento ante el cabildo conquense de respetar y cumplir sus usos y costumbres, indicándose que hasta ese momento no había acudido a Cuenca $^{29}$. De hecho, ya hemos visto cómo le interesaba sobremanera conseguir recaudar los emolumentos que le proporcionaban el arcedianato y sus otros beneficios, al arrendar la recaudación de sus rentas. Y, además, hay un dato que nos hace sospechar su presencia en Salamanca. Casi a mediados de 1419, en concreto el 19 de mayo, llegaba a un acuerdo con Rodrigo Bernal, arcediano salmantino, para intercambiarse la procuración de sus respectivos arcedianato $^{30}$. Evidentemente con ello el prebendado mostraba un claro interés por trasladar sus rentas, en la medida de lo posible a Salamanca. Esto, efectivamente, lo conseguiría con el tiempo, llegando a un intercambio total de los arcedianatos. Así, en 1429 consta como arcediano de Salamanca (y no de Alarcón), y viceversa ocurría con Bernal ${ }^{31}$.

Otro dato que nos invita a pensar que efectivamente estuvo estudiando en Salamanca son sus propias peticiones a la Curia, así como la forma en que es mencionado en los documentos que emanan de ella. De este modo, en el mencionado documento de 1429, aparece mencionado como bachiller en decretos (muestra de su paso por la universidad) ${ }^{32}$. Años después, en diciembre de 1433 y siendo ya electo uxamense, pediría y recibiría la licencia para poder ser examinado del grado de doctor fuera del estudio, pues, según aseguraba, después del bachillerato siguió estudiando varios años en Salamanca ${ }^{33}$. De este modo, podemos saber que efectivamente estudió en aquella universidad y que allí alcanzó el grado de bachiller, aunque, seguramente, no llegó nunca a licenciarse (no sería el primer caso de prelado o persona con contactos y apoyos que se saltaba ese escalón para acceder al doctorado directamente ${ }^{34}$ ). Así se pone de manifiesto cómo, pese a sus intentos de estar cerca de la Universidad, no debió ser un estudiante especialmente brillante.

29 A C Cuenca, Secretaría, Actas capitulares, Libro III, f. 19r.

30 Ibídem, f. 23v. Dado el mayor valor de las rentas conquenses, acordaban que, en caso de recibir menos dinero Castilla, Bernal le entregaría hasta 30 florines de las rentas conquenses.

31 BELTRÁN DE HEREDIA, V., Bulario de la Universidad..., II, doc. 809, p. 334.

32 Ibídem.

33 Ibídem, doc. 873, p. 388.

34 Véase otro ejemplo: Gutierre de Toledo, que consiguió ser absuelto en un caso de asesinato y, además, el título de doctor, NIETO SORIA, J.M., Un crimen en la corte. Caída y ascenso de Gutierre Alvarez de Toledo, señor de Alba (1376-1446), Madrid, 2005, p. 161-168. 


\section{EL APOYO DE JUAN II: EL EPISCOPADO}

Como vemos, el prelado siguió desarrollando su actividad en el seno de la Iglesia, pero desde la desaparición de su prima y benefactora, la reina Catalina de Lancáster, su carrera se había visto estancada. En todo esto, sin duda, tuvo una notable relevancia los avatares políticos de los primeros años del reinado, así como el hecho de que cuando la reina muriese la carrera de Pedro de Castilla fuese poco más que un proyecto.

Juan II de Castilla se caracterizó en sus primeros años de reinado por un intento constante de afianzar su poder frente a la nobleza que se aglutinaba en torno a sus primos los infantes de Aragón. Para ello, se sirvió de cuantos elementos tuvo a su alcance, y qué duda cabe que uno de ellos eran aquellos que habían servido a su madre. Estos le ofrecían una notable experiencia administrativa y política, y también la resistencia a las peticiones del bando aragonesista. Este tipo de actuación de Juan II de Castilla la podemos ver en algunos de los colaboradores que le sirvieron en esos primeros años, que ya habían tenido relevancia en el servicio a su madre: Fernando Martínez Dávalos, Juan Rodríguez de Villalón y, sobre todo, Álvaro Núñez de Isorna ${ }^{35}$.

Las primeras actuaciones de Juan II sobre Pedro de Castilla podrían interpretarse en ese sentido. Es muy posible que a finales de la década de los años 20 del siglo xv el monarca se diese cuenta de que algunos de sus colaboradores tenían escaso futuro político debido a su edad, por lo que era el momento de ir buscando quien les pudiese reemplazar. El caso de Pedro de Castilla sería un buen ejemplo, pues desde finales de esa década podemos encontrar un repunte en sus actividades y en las menciones que hay de él en la documentación. En concreto, a principios de diciembre de 1429 solicitó dispensa para poder optar a otro beneficio incompatible ${ }^{36}$. Fruto de esta petición, seguramente, aparece mencionado como canónigo de Cuenca en octubre de 1432, al tiempo que mantenía el arcedianato de Salamanca ${ }^{37}$. En ese momento, además, solicitó al papa dispensa para poder recibir cualquier dignidad además de las que ya tenía. Eugenio IV accedió alegando que era descendiente ilegítimo de un rey ${ }^{38}$. Es la primera mención a sus orígenes regios y no será la última. En mi opinión es muy posible que el rey ya se hubiese fijado en él por entonces.

Efectivamente, tan solo tres meses después, en enero de 1433, era promovido a la sede uxamense por petición regia, para lo que desplazó, incluso, a Juan Alfonso de Mella, embajador regio ante el papa y protegido de éste ${ }^{39}$. Así, Juan II, sobrino suyo, había sido fundamental a la hora de conseguir que Pedro de Castilla

35 Véase al respecto VILLARROEL GONZÁLEZ, O., Las relaciones Monarquía-lglesia..., pásim; especialmente el apéndice prosopográfico.

36 BELTRÁN DE HEREDIA, V., Bulario de la Universidad..., II, doc. 809, p. 334.

37 Ibídem, doc. 850, p. 370.

38 Ibídem.

39 Ibídem, doc. 858, p. 376. 
culminase su carrera eclesiástica con el ascenso al episcopado. Con ello había continuado lo que ya iniciase su madre, y se ganaba aparentemente un colaborador para el futuro.

Desde ese momento aparece al servicio regio en labores diplomáticas. Así, poco tiempo después de su nombramiento, y ante el fallecimiento de Juan Martínez Contreras, el rey le nombraba miembro de la comisión negociadora con Aragón y Navarra, en sustitución del difunto arzobispo ${ }^{40}$. Además, participaba en las recepciones de eran objeto los embajadores franceses en la villa de Madrid ${ }^{41}$. Buen ejemplo de ese ascenso, y de cómo el rey tenía sus esperanzas y confianza puestas en él, es cómo en el momento de ser nombrado diputado para la negociación con Aragón era mencionado como oidor del Consejo, y cómo en enero de 1435 ya aparece mencionado como oidor de la Audiencia Real ${ }^{42}$.

Buen ejemplo de esa actividad regia, y de la decisión que tenía de encumbrar a su tío, la encontramos en los meses siguientes a esta última noticia. Desde enero hasta mayo de ese año el monarca lucharía tenazmente por conseguir para Pedro de Castilla el arzobispado hispalense, vacante por el traslado de Cerezuela a Toledo. Efectivamente, ya el 12 de enero el rey intentó que el cabildo hispalense le eligiese como arzobispo ${ }^{43}$. No debió conseguir su objetivo, encontrando resistencia en el seno del cabildo, pues a principios de mayo escribía a Pedro de Vaca, arcediano de Sevilla, para que convenciese al cabildo de la elección de Castilla como nuevo arzobispo ${ }^{44}$.

Ese no sería el único frente que abriese Juan II. Tan sólo trece días después el rey había escrito ya varias cartas al papa, intentando conseguir el traslado de la sede uxamense a la hispalense. También fue en vano, puesto que Eugenio IV le indicó que, desgraciadamente, ya había entregado esa sede a Diego de Anaya, y que los documentos habían sido expedidos por la cancillería, con lo que no podía hacer nada ${ }^{45}$. Así, se muestra claramente la intención regia de promocionar a su familiar en la jerarquía eclesiástica castellana. Qué duda cabe que con ello estaba labrando la carrera de un colaborador, pudiendo encontrar notables semejanzas con Martínez Contreras o con Juan de Cerezuela (ambos arzobispos se vieron repetidamente favorecidos por el rey). De haberlo conseguido, habría podido contar con fieles personajes en las tres sedes arzobispales castellanas, puesto que en Toledo estaba Cerezuela, y en Compostela Lope de Mendoza. Este sería el punto más alto de las perspectivas de la carrera eclesiástica de Pedro de Castilla, al ser lo más cerca que estuvo de alcanzar una sede arzobispal.

40 GARCÍA DE SANTA MARÍA, A., Crónica de Juan II, C, p. 404.

41 VILLARROEL GONZÁLEZ, O., «Pedro de Castilla...», p. 145-146; Refundición..., p. 168; CARRILLO DE HUETE, P., Crónica del Halconero..., p. 179.

${ }^{42}$ A M Sevilla, Actas Capitulares, 1435, f. 31; SANZ FUENTES, M.J., y SIMO RODRÍGUEZ, M.I., Catálogo de los documentos contenidos en los libros del cabildo del concejo de Sevilla, Sevilla, 1993 , p. 11.

43 Ibídem.

44 A C Sevilla, Fondo histórico, leg. 185, 7/3.

45 BELTRÁN DE HEREDIA, V., Bulario de la Universidad de Salamanca, II, p. 399, citando: A S Vaticano, Reg. Avin., 373, f. 208. Empero, le indicaba que no cejaría en el futuro en tratar de favorecerle. 
Sin embargo, su carrera política no se detuvo y el rey seguramente esperaba otra oportunidad para poder promoverle. Desde 1435 hasta marzo de 1439 su actividad junto al rey y a su servicio sería constante. Por un lado destaca su vertiente ceremonial y simbólica, participando activamente en muchos actos que tenían un claro matiz propagandístico, como las ceremonias que se desarrollaban en la corte. Así, en 1435 participó en el bautizo de Juan, hijo de Álvaro de Luna, siendo padrinos los mismos reyes ${ }^{46}$. A mediados de 1436 seguía siendo miembro del Consejo Real ${ }^{47}$. La cercanía al rey queda clarificada cuando comprobamos cómo él fue el encargado de realizar la ceremonia de toma de manos entre el príncipe Enrique y la princesa navarra, Blanca, en 1437 en Alfaro ${ }^{48}$.

Su grado de colaboración con el rey aparentemente era conocido incluso fuera de Castilla, puesto que fue elegido por el papa para actuar como comisionado en un pleito de Álvaro de Luna, sin duda para evitar que se viese perjudicado ${ }^{49}$. No fue la única ocasión en que el obispo fue nombrado para defender los intereses regios. En 1437 Eugenio IV le comisionó para que pudiese sentenciar en las causas que el rey promoviese contra los eclesiásticos que se amparasen en su estado para no pagar alcabalas y otros derechos ${ }^{50}$.

¿Cómo es mencionado a lo largo de estos años en la documentación y crónicas conservadas? La verdad es que existe una cierta variabilidad. La mayor parte de las veces es mencionado como obispo de Osma y nieto del rey Pedro I.

Las primeras menciones a él en la cronística aparecen en la Crónica de Juan I/ de Alvar García de Santa María. Esto tiene cierta relevancia, dado que la narración de este cronista fue realizada poco tiempo después de los hechos, y porque nos puede mostrar también un claro matiz en cómo transmite las cosas: la existencia de una visión regia de la realidad ${ }^{51}$. Hay que tener en cuenta que esta parte de la obra de García de Santa María fue revisada e influida por Fernando Díaz de Toledo y el condestable ${ }^{52}$, pero, como veremos, eso no impide que se muestre la posición del rey respecto al prelado.

$\mathrm{Y}$, efectivamente, en la forma en la que se presenta a Pedro de Castilla podemos ver una cierta influencia de la visión regia. Así, la primera vez que es mencionado es en el momento de presentar cómo el rey consiguió que se le proveye-

46 Refundición..., p. 186; Crónica de don Álvaro de Luna..., p. 146; GALÍNDEZ DE CARVAJAL, L., Crónica de Juan II de Castilla..., p. 534.

47 Sección Nobleza del Archivo Histórico Nacional, Osuna, leg. 1740, n. ${ }^{\circ 2}$ (carp. 179, n. ${ }^{\circ} 17$ ).

48 Refundición..., p. 215.

49 Sobre el pleito y la participación del prelado, véase: VILLARROEL GONZÁLEZ, O., Las relaciones entre el arzobispado de Toledo y la Monarquía en tiempos de Juan Il de Castilla (1406-1454), Toledo, 2003, pp. 214-216; sobre éste último aspecto puede verse también mi «Pedro de Castilla...», pp. 142143.

50 Archivo General de Simancas, Estado-Roma, leg. 847, n. ${ }^{\circ} 84$, p. 4; véase en VILLARROEL GONZÁLEZ, O., «El papado y la monarquía de Juan II de Castilla (1406-1454) en un inventario de la documentación pontificia de los Reyes Católicos», En la España Medieval, 23 (2000), pp. 137-187, p. 181.

51 GÓMEZ REDONDO, F., Historia de la prosa medieval..., pp. 2.233-2.234.

52 Así lo indica Gómez Redondo, ibídem, pp. 2.210-2.211. 
se de la sede uxamense. El rey presentó al papa la súplica para que le entregase la sede a «Pedro, nieto del rrey don Pedro, hijo de un hijo que el rrey don Pedro hobiera non legítimamente, el cual estaba en estudio por mandato del rey»53. Así, se le presenta como familiar de Juan II, así como su interés por su formación y promoción. Y no es baladí el hecho de que se muestre cómo era nieto ilegítimo de Pedro I, de forma que no se perjudicase la propia legitimidad regia.

Esta forma de presentación de Pedro de Castilla se repetirá a lo largo de la crónica de Alvar García de Santa María. En 1434 se indica cómo el papa intentó entregarle la sede seguntina, en contra de los deseos regios, que ya la había solicitado para Alfonso Carrill ${ }^{54}$. Incluso en ese caso, que se actuaba en contra de los intereses de Pedro de Castilla, se plasma cómo era cercano al rey, pues se sigue indicando su familiaridad: «don Pedro, nieto del rrey don Pedro». Hay que tener en cuenta que se estaba promocionando a un familiar del condestable, que situaba sus intereses por encima de los del rey. En este punto hemos de ver la mano de Fernando Díaz de Toledo que comentaba Gómez Redondo, pero también la de García de Santa María en la nominación que se da a Pedro de Castilla.

Aún encontramos una última mención al prelado antes de que el tronco cronístico se divida. Ese mismo año de 1434 se indica cómo fue nombrado diputado para negociar con Aragón en sustitución de Martínez Contreras, que había fallecido. Dice de él simplemente «obispo de Osma», sin embargo a continuación indica «el cual fue luego sobre ello donde los otros diputados estaban, e después, con licencia del rrey, volvió a la Corte. Este obispo era oidor del Consejo del Rey „55. Se menciona de nuevo su cercanía al rey, cómo pertenecía a su círculo más cercano (el Consejo) y cómo Juan II confiaba en él hasta el extremo de involucrarle en tareas diplomáticas, aunque luego le hiciese volver a la corte.

Desde este momento, cuando calla la crónica de García de Santa María, la forma en la que se presenta al prelado varía según la obra de la que se trate, pues puede alternar la fórmula empleada para el mismo hecho. Atenderemos, a partir de aquí, a las diversas crónicas o redacciones conservadas: la Crónica del Halcone$r^{56}$, la Refundición de la crónica del halconero ${ }^{57}$, la Crónica de don Álvaro de Luna $^{58}$, y la Crónica de Juan I/ recopilada por Galíndez de Carvajal ${ }^{59}$, atribuible, en el periodo que se le atiende, también a Fernán Pérez de Guzmán ${ }^{60}$.

Así, en el momento de narrar el bautizo de Juan, hijo del condestable Luna, celebrado en Madrid por Pedro de Castilla, se le menciona mayoritariamente como nieto del rey Pedro I. Por esa fórmula se decantan la Crónica del Halconero ${ }^{61}$, la

\footnotetext{
53 GARCÍA DE SANTA MARÍA, A., Crónica de Juan II..., p. 377.

54 Ibídem, p. 391.

55 lbídem, p. 409.

56 CARRILLO DE HUETE, P., Crónica del halconero ...

57 Refundición de la crónica del halconero...

58 Crónica de don Álvaro de Luna...

59 GALÍNDEZ DE CARVAJAL, L., Crónica de Juan I/ de Castilla...

60 GÓMEZ REDONDO, F., Historia de la prosa medieval..., p. 2.264.

61 CARRILLO DE HUETE, P., Crónica del halconero..., p. 211.
} 
Refundición de la crónica del halconero ${ }^{62}$, la Crónica de Juan $1{ }^{63}$ y la Crónica de don Álvaro de Luna ${ }^{64}$. Tan sólo la llamada Abreviación del halconero se desmarca y alude a él simplemente como obispo de Osma ${ }^{65}$.

Tan sólo el Halconero y la Refundición de la crónica del halconero atienden a su participación en la recepción de los embajadores franceses en Madrid en 1434, y ambos aluden a él de la misma manera, diciendo que era «nieto del rrey don Pedro, obispo de Osma» ${ }^{66}$.

Su participación en la ceremonia de la toma de las manos entre el príncipe Enrique y la princesa Blanca de Navarra, realizada en territorio navarro, también fue recogida por tres de las crónicas. En concreto la Abreviación y la Crónica del halconero se refieren a él simplemente como «obispo de Osma» ${ }^{67}$, mientras que la Refundición lo hace con el ya conocido «obispo de Osma, nieto del rrey don Pedro»68.

En cuanto a su actuación como consagrante de Lope de Barrientos como obispo de Segovia existe más unanimidad. Todas las crónicas le mencionan en su calidad de nieto de Pedro I, indicando que era «obispo de Osma, nieto del rrey don Pedro»69.

Sólo hay un par de menciones más al prelado en este periodo. La primera es cuando, en 1438, el monarca sale de Madrigal con tropas en persecución del almirante, mencionándose, junto a otros, a Pedro de Castilla, sólo como obispo de Osma $^{70}$. La segunda, cuando, tras la sublevación nobiliaria, el rey llega hasta Roa de Duero, esquivando la ciudad de Valladolid, donde estaban los rebeldes. Junto a los que allí acuden con el monarca es mencionado Pedro, "obispo de Osma, nieto del rrey don Pedro » ${ }^{71}$.

Como vemos, de forma generalizada se le menciona tanto con su cargo episcopal como con su parentesco con el rey Pedro I. Esto tiene un notable peso, pues pone de manifiesto cómo se le incluía, si quiera de forma lejana, dentro de la nobleza de sangre regia. Además, hay que tener en cuenta que el parentesco de la reina Catalina con el rey Pedro I era conocido, con lo que se le relacionaba directamente con la familia real. Por ello su mención no dejaba de tener relevancia simbólica, al incluírsele en el entorno familiar regio.

62 Refundición..., p. 186.

63 GALÍNDEZ DE CARVAJAL, L., Crónica de Juan I/ de Castilla..., p. 524.

64 Crónica de don Álvaro de Luna..., p. 146.

65 Abreviación del halconero, Biblioteca de Santa Cruz, ms, 434, f. 91v.

66 Este parecido puede deberse al parentesco de ambos manuscritos. CARRILLO DE HUETE, P., Crónica del halconero..., p. 179, y Refundición...,p. 168. Es digno de mención, a la hora de apreciar la mano de Galíndez sobre el original de Pérez de Guzmán, como este fragmento no es incluido en la Crónica de Juan I/ que él recopila.

67 Abreviación..., f. 103v; CARRILLO DE HUETE, P., Crónica del halconero..., p. 247.

68 Refundición..., p. 215.

69 Abreviación..., f. 107v; Refundición..., p. 221; P. Carrillo de Huete, Crónica del halconero..., p. 247, en este caso existe una variación gráfica, el escribir «nyeto», diferencia sin mayor impotancia.

70 GALínDEZ DE CARVAJAL, L., Crónica de Juan I/ de Castilla..., p. 548.

71 Refundición..., p. 223. 
Como vemos, las referencias que se hacen a él alternan entre la mención o no de su ascendencia regia. Es interesante, en este sentido, comprobar cuáles son las obras que lo hacen y cómo. Así, la Abreviación habla de él siempre como obispo de Osma, salvo en la consagración de Barrientos (un total de 1 mención sobre 4). La Crónica del halconero, en cambio, muestra mayoritariamente su relación con Pedro I, salvo en la ceremonia de toma de manos entre los príncipes castellano y navarra (un total de 3 sobre 4). La Refundición va más allá, al mencionarle siempre como nieto del rey Pedro (un total de 5 sobre 5). La Crónica de Juan II, recopilada por Galíndez de Carvajal, le cita dos veces, utilizando una vez cada fórmula. Y por último, la Crónica de don Álvaro de Luna sólo le menciona una vez y lo hace como nieto del dicho rey. En líneas generales podemos apreciar que su ascendencia se menciona en un total de 11 ocasiones sobre 15 , lo que supone un $73 \%$ de los casos analizados.

Pero los datos transmitidos toman mayor relevancia si tenemos en cuenta quién hace esas menciones, la autoría de cada obra. Así, es digno de mención que sea Pedro Carrillo quien más énfasis pone en las menciones de Pedro de Castilla, sobre todo en el momento en el que el rey está intercediendo para conseguir su ascenso. La posición de Pérez de Guzmán al respecto no le va a la zaga, puesto que se le menciona de la misma manera siempre. En el caso de la recopilación hecha por Galíndez, que utiliza en este punto al anterior, tiene alguna variante ${ }^{72}$. Así, la persona de Pedro de Castilla queda envuelta en un halo de independencia a los ojos de Pérez de Guzmán, más cercano al bando nobiliario. Esto se refuerza al ver la visión que se le aplica en la crónica del condestable, con una posición ideológica opuesta a la de Pérez de Guzmán, como es la Crónica de don Álvaro de Luna.

Estos datos se ven confirmados por los que nos transmite la documentación. Y para este periodo tenemos la suerte de contar con una misiva regia en la que Juan II se refiere a Pedro de Castilla. En concreto, el 4 de mayo de 1435 escribía al arcediano de Valpuesta, Pedro de Vaca, para que convenciese al cabildo de Sevilla, al que pertenecía, de que eligiesen a Pedro de Castilla como arzobispo hispalense (vacante al trasladarse Cerezuela a Toledo). Pues bien, en esa misiva el rey les indicaba que debían elegir al obispo de Osma, su tío ${ }^{73}$. Así pues, el rey marcaba claramente su posición ante el prelado, al que mencionaba como miembro de su propia familia.

De este modo, parece confirmarse lo que las crónicas nos presentan, el interés regio por alzar al personaje se manifiesta en la aceptación de una relación familiar entre ambos, lo que supone una aceptación regia, lo que fue, a su vez, reflejado por los escritores. Si atendemos a cómo se le menciona tanto en las crónicas como en la documentación, nos encontramos con una clara característica del prelado: el reconocimiento de su relación con la familia real, así como su ascendencia regia.

72 Podemos achacarlas al propio Galíndez, más atento a representar la imagen regia que le interesaba en su programa cronístico que en mantener la de otros que, en su momento, habían perdido importancia.

${ }^{73}$ A C Sevilla, Fondo histórico, leg. 185, 7/3. 
Esto fue un rasgo común con otros miembros del linaje, junto a la mención recurrente a ser «nieto» o «nieta» del «rey don Pedro», que apelaban a su ascendencia como formas simbólicas de su legitimación y ensalzamiento ${ }^{74}$. En este caso nos encontramos con el uso superlativo de esa fórmula, al conseguir extenderlo a la cronística y que el rey reconozca ese parentesco ${ }^{75}$.

Así, podríamos afirmar que la figura de Pedro de Castilla durante estos años había conseguido una total aceptación, así como el reconocimiento de su filiación regia. En esto tuvo una gran importancia la propia posición de don Juan II, por el respaldo que le dio en su carrera eclesiástica y por la defensa que hacía de su relación (sin duda el hecho de que el mismo Juan II le mencionase como su «tío» en la misiva enviada a Sevilla es un claro ejemplo al respecto). De hecho, se puede afirmar que el rey apostaba claramente por Pedro de Castilla, y que había de ver en él a un servidor con gran futuro de quien esperaba recibir un gran apoyo, tal y como veremos en el momento de la ruptura.

\section{EL OBISPADO DE PALENCIA: EL ESTANCAMIENTO}

Los movimientos políticos desarrollados en Castilla desde 1438 dieron a Pedro de Castilla la oportunidad de intentar avanzar en su carrera por medio de una participación activa e independiente de la posición regia. Para ello no dudó en situarse junto a la nobleza rebelde, pensando que así podría obtener mayores beneficios para una carrera que, después de la experiencia hispalense, podía pensar que estaba estancada. Si bien en un primer momento logró ciertos éxitos, a la larga supuso más un perjuicio que un beneficio.

El cambio en el prelado fue rápido. El 21 de febrero aún aparecía junto al rey cuando éste acudía desde Medina del Campo hacia Roa por el alzamiento del adelantado $^{76}$. Desde allí el prelado debió seguir camino hacia la sede de su obispado, seguramente tramando ya su cambio de posición. Este se hace manifiesto ya el día 9 de marzo (dieciocho días después) cuando hizo público su apoyo a las reclamaciones de los rebeldes y lo representó tomando ciertas fortalezas de su sede que tenía en guarda Álvaro de Luna ${ }^{77}$. El rey se sorprendió, e intentó que acudiese junto a él, tal vez para conocer la razón de su actitud e intentar congraciarse con él.

${ }^{74}$ GONZÁLEZ DE FAUVE, M.E., LAS HERAS I.J., y DE FORTEZA, P., «Simbología del poder en un linaje castellano: los descendientes de Pedro I excluidos de la línea sucesoria», Cuadernos de Historia de España, 78 (2003-2004), pp. 47-66, especialmente notas 25 y 26.

75 Eso muestra la cercanía entre rey y prelado. Otro ejemplo lo encontramos en Catalina de Castilla, priora de Santo Domingo el Real de Toledo, a quien Juan II, Enrique IV y los Reyes Católicos protegieron, y a quien llamaban «tía», en reconocimiento de ese parentesco. MESEGUER FERNÁNDEZ, J., «Santa Beatriz de Silva en Santo Domingo el Real de Toledo, de monjas dominicas», Anales Toledanos, XIV (1982), p. 96.

76 CARRILLO DE HUETE, P., Crónica del Halconero..., p. 262; GALÍNDEZ DE CARVAJAL, L., Crónica de Juan II de Castilla..., p. 550.

77 CARRILLO DE HUETE, P.Crónica del Halconero..., p. 262; GALÍNDEZ DE CARVAJAL, L., Crónica de Juan II de Castilla..., p. 550. 
Así, sabemos que le hizo llegar un seguro para que acudiese a él. El prelado no pasaría del Burgo de Osma, sin llegar hasta Roa donde seguía el rey ${ }^{78}$. De hecho, aprovecharía la marcha regia hacia Olmedo para acudir a Valladolid y unirse a los rebeldes entre mediados y finales de ese mismo mes de marzo ${ }^{79}$. Así, en apenas mes y medio había pasado desde el servicio regio a la toma de posición junto a los rebeldes.

A lo largo de 1439 mantuvo su posición junto a los sublevados. El monarca no dudó en recriminar tal actuación por su parte, al tiempo que él obtuvo beneficios de ello. Así, si por un lado era mencionado entre los que revolvían el reino ${ }^{80}$, por otro lado en menos de un año consiguió ser trasladado a Palencia, una sede más rica. Ya el 6 de abril de 1440 tenía el nuevo cargo de obispo de Palencia, el cual le había sido conferido por el papa ${ }^{81}$.

¿Cómo había llegado a obtener un prelado opuesto al monarca una sede episcopal si las concesiones que el papado había hecho a Juan II especificaban que se atendería sus peticiones al respecto ${ }^{82}$ ? En este sentido se plantean tres posibilidades. Por un lado, que el prelado consiguiese que el monarca se viese obligado a solicitar la sede para él por el ambiente político. Esto, que hubiera sido posible pocos años después, aún parece improbable entre 1439 y 1440. La segunda opción es que solicitase la sede con la esperanza de atraérselo (como ya había ocurrido con la sede tudense y el conde de Benavente y su hermano Luis de Pimentele3). Por último, cabe la posibilidad de que el mismo prelado se postulase ante el papa e, incluso, que esgrimiese su posibilidad de pagar por adelantado la anata para convencer al pontífice ${ }^{84}$. Dada su personalidad no sería extraña la aceptación de su petición en Roma, pues allí era conocida su relación con Juan II, además de la notable influencia que la propia situación del pontificado romano podía tener en toda la cuestión.

Es difícil saber qué ocurrió exactamente. La cuestión se complica un poco más, si cabe, si tenemos en cuenta que en octubre de 1439 hubo una reunión del cabildo palentino para la elección de nuevo prelado. Efectivamente, sabemos que en noviembre de 1439 Alfonso Rodríguez de Maluenda, canónigo de Burgos y Palencia, informaba en Burgos que debía acudir a Palencia para la elección del

${ }^{78}$ CARRILLO DE HUETE, P., Crónica del Halconero..., p. 282.

79 VILLARROEL GONZÁLEZ, O., «Pedro de Castilla...», p. 150; GALÍNDEZ DE CARVAJAL, L., Crónica de Juan II de Castilla..., p. 552; CARRILLO DE HUETE, P., Crónica del Halconero..., p. 282.

${ }^{80}$ Archivo General de Simancas, Patronato Real, leg. 12, n. ${ }^{\circ} 30$.

81 A S Vaticano, Cam Ap., Obl. Comm., 66, f. 51r.

82 Como se sabe, desde 1421, con la bula Sedis Aposolicae el papa debía escuchar las peticiones regias. Además, el rey podía instar a los cabildos a la elección de personas determinadas. Véase: NIETO SORIA, J.M., Iglesia y génesis..., pp. 363-368; «El pontificado de Martín V y la ampliación de la soberanía real sobre la Iglesia castellana (1417-1431)», En la España Medieval, 17 (1994), pp. 113-131, p. 128.

83 VILLARROEL GONZÁLEZ, O., Las relaciones Monarquía-Iglesia..., pp. 1.002-1.003.

${ }^{84}$ Esta misma estrategia la utilizó años después cuando aspiró a la sede arzobispal toledana a la muerte de Juan de Cerezuela, véase: NIETO SORIA, J.M., «Dinero y política en torno a una vacante episcopal: la provisión de Toledo en 1442», en Escritos dedicados a José María Fernández Catón, León, 2004, pp. 1.059-1.071, especialmente pp. 1.068 y 1.070. 
nuevo prelado ${ }^{85}$. Esto no era canónico, puesto que el antecesor en la sede había sido traslado por el papa a la sede hispalense, por lo que le atañía a él elegir al sucesor $^{86}$. Así, se nos plantea la duda de quién hizo que el cabildo tratase de llevar a cabo una elección que no tenía muchos visos de conseguir su fin. Parece lógico que el rey buscaase que el cabildo eligiese a alguien favorable a su persona, y no sería la única vez que el rey intentase una maniobra semejante ${ }^{87}$, y parece menos posible que un prelado rebelde al rey consiguiese movilizar a todo un cabildo para conseguir su elección.

Sea como fuere, el nombramiento fue firme, y el día 13 de julio de 1440 un procurador suyo se presentaba ante el cabildo mostrando unas letras apostólicas en las que se hacía provisión de la sede en Pedro de Castilla, para que fuese aceptado como tal, lo que efectivamente se hizo ${ }^{88}$.

Los meses siguientes supusieron una notable actividad política del nuevo prelado palentino. Hasta 1442 es mencionado de forma recurrente participando en los conflictos y negociaciones políticas. Su cercanía al infante Juan queda patente. Tan solo dos meses después de tomar posesión de la nueva sede fue uno de los miembros de la comitiva que salió a recibir a la princesa navarra, hija del infante, que acudía para celebrar su matrimonio con el príncipe Enrique ${ }^{89}$. Menos de un año después, en junio de 1441, aparece negociando en nombre del infante Juan ${ }^{90}$. $Y$ una vez que estos tomasen el poder con el apoyo de la reina María, aparece de nuevo en del Consejo Real, en septiembre de $1441^{91}$.

Sin embargo ya por entonces nos encontramos con el primer síntoma de lo que sería su caída en desgracia: el papa le escribió para convocarle en la Curia para tratar sobre su desunión con el rey ${ }^{92}$, y poco antes el cabildo de Palencia daba orden de revisar las cuentas del prelado ${ }^{93}$. Como vemos, la intervención desde el

85 SERRANO Y PINEDA, L., Los conversos don Pablo de Santa María y don Alfonso de Cartagena. Obispos de Burgos, gobernantes, diplomáticos y escritores, Madrid, 1942. p. 188.

${ }^{86}$ Sobre la normativa en cuanto a las elecciones episcopales, y los cambios que había tenido a lo largo de la Baja Edad Media, véase el análisis que ya realicé anteriormente en: VILLARROEL GONZÁLEZ, O., «Las elecciones episcopales en la primera mitad del siglo xv. Realidad y representación de la «libertas» eclesiástica», Actas del I Simposio de Jóvenes Medievalistas. Lorca 2002, Murcia, 2003, pp. 261273.

87 Años después hizo algo parecido en el caso cauriense: VILLARROEL GONZÁLEZ, O., «Un ejemplo de la intervención regia en las elecciones episcopales. Fernando de Sotomayor, electo de Coria», Revista de Estudios Extremeños, LVIII (58, 2002), pp. 1.031-1.045.

88 A C Palencia, Actas Capitulares, libro 8, ff. 65r; documento publicado por FRANCIA LORENZO, S., Archivo Capitular de Palencia. Catálogo serie II. Actas capitulares, Palencia, 1989, 2 vols., II, p. 142.

89 CARRILLO DE HUETE, P., Crónica del Halconero..., pp. 343 y 345; GALÍNDEZ DE CARVAJAL, L., Crónica de Juan I/ de Castilla..., p. 565-567.

90 GALÍNDEZ DE CARVAJAL, L., Crónica de Juan I/ de Castilla..., p. 584, CARRILLO DE HUETE, P., Crónica del Halconero..., pp. 410-412.

${ }^{91}$ Biblioteca de la Real Academia de la Historia, colección Salazar y Castro, 9/816, ff. 220-251v.

92 A S Vaticano, Reg. Vat., 359, ff. 131v-132r; documento publicado por BELTRÁN DE HEREDIA, V., Bulario de la Universidad de Salamanca, II, doc. 996, p. 484.

93 Ya indiqué anteriormente cómo esto podía ser una forma del cabildo de atacar a un prelado opuesto al rey. No en vano tal orden se emitía a la vez para Gutierre Gómez de Toledo y Pedro de Castilla, ambos enfrentados a Juan II. VILLARROEL GONZÁLEZ, O., Las relaciones Monarquía-Iglesia..., p. 483. 
pontificado es clara: apoyar a la Monarquía socavando la posición de uno de los miembros de la oposición. No hay datos fehacientes de que obedeciese ese mandato pontificio, aunque podemos sospechar que, efectivamente, lo hizo. El 13 de septiembre de ese año aún estaba en Castilla, pues aparece como uno de los miembros del Consejo que confirman el seguro dado al condestable tras la toma del poder por parte de los infantes ${ }^{94}$. La siguiente noticia que nos lo presenta en Castilla no se da hasta el 14 de junio de 1442, casi un año después, cuando aparece de nuevo como consejero ${ }^{95}$. En el ínterin, tan sólo hay una noticia sobre él, que nos indica que presionaba fuertemente para conseguir el arzobispado de Toledo en febrero de $1442^{96}$. ¿Presionaba desde Roma para conseguir la sede? Es posible, tal y como aparece mencionado en las cartas del embajador de Fernán Álvarez de Toledo, que el prelado estuviese en Roma en esos momentos, y que aprovechase su estancia en la Curia para solicitar para sí la sede toledana, respaldando económicamente, y en persona, su petición ${ }^{97}$.

Es posible pensar que su visita a la Curia, o la reconvención de Eugenio IV, hiciese efecto, pues desde ese momento el prelado deja de aparecer como uno de los principales actores políticos de la sublevación. En este sentido, también puede que tuviese cierta influencia el hecho de que, pese al apoyo prestado a los sublevados y en especial a los infantes, éstos hubiesen preferido apoyar a Gutierre de Toledo como nuevo primado toledano. Efectivamente, las crónicas nos informan de que los infantes habían presionado al rey para aceptar a éste como primado, «porque ya don Gutierre, arzobispo de Sevilla, era concordado con ellos, y quisiéranlo para él’’98. Esto tuvo que afectar a la disposición del prelado para colaborar con los sublevados y los infantes, puesto que Gutierre de Toledo se les había opuesto desde el principio, y sin embargo era favorecido antes que él, que había arriesgado su carrera y posición abandonando al rey para apoyarles.

Sea como fuere, lo cierto es que el prelado va a desaparecer durante muchos años de la vida política castellana. En este hecho seguramente tuvo que ver tanto su propia decisión como, indudablemente, la del rey. Juan II había visto cómo el prelado, a quien él había ascendido y protegido, en quien había confiado, le había traicionado en un momento de necesidad. Esto tuvo que influir mucho en su alejamiento de la corte y de la vida política ${ }^{99}$.

¿Cómo se le menciona durante este periodo al prelado? Durante estos años se produjo un cambio relevante en la forma en la que se refieren las crónicas y los documentos a Pedro de Castilla. El mejor ejemplo de ello podemos verlo en las últimas menciones que Pedro Carrillo de Huete hizo a él en su Crónica del halconero.

94 Biblioteca de la Real Academia de la Historia, colección Salazar y Castro, 9/816, ff. 220-251v.

95 Biblioteca Nacional, ms. 13.259, f. 332 y ss.

96 GALÍNDEZ DE CARVAJAL, L., Crónica de Juan II de Castilla..., p. 607-608.

97 ACDA, leg. 222-5, sin número de documento; publicado por NIETO SORIA, J.M., «Dinero y política...», pp. 1.067-1.069.

98 GALÍNDEZ DE CARVAJAL, L., Crónica de Juan // de Castilla..., p. 607.

99 VILLARROEL GONZÁLEZ, O., «Pedro de Castilla...», pp. 155-156. 
Así, en marzo de 1439, cuando el prelado se sitúa junto a los sublevados, aparece mencionado por última vez como «nyeto del rrey don Pedro» ${ }^{100}$. Esta crónica, además, es el mejor indicativo de cómo vio el rey la unión de Pedro de Castilla a los sublevados:

«e desque lo sopo el rrey ovo grand sentimiento por fazer tales cosas en tales tiempos; enviole sus cartas de seguro, que viniese a su merced, e vino éste desde Gómara, donde estaba, fasta El Burgo. E desde que allý estovo no quiso llegar a Roa, donde estaba el rrey».

Esta mención a cómo vio Juan II la traición del prelado, dado el autor ${ }^{101}$, podemos darla por cierta, y no hacerla pasar por pura dramatización. Con ello se estaría mostrando tanto la desazón del rey al ver cómo uno de sus colaboradores (y a quien él estaba tratando de promocionar) le abandonaba, como los intentos de conseguir que volviese a su servicio y dejase de apoyar a los rebeldes. Sin embargo, desde este momento la forma en que se menciona al prelado cambia drásticamente, sin duda por la respuesta del prelado: seguir en la sublevación y entrar en Valladolid con los nobles y prelados rebeldes. Si Carrillo de Huete mencionaba antes su parentesco con la realeza al indicar que era nieto de Pedro I, desde ese momento deja de hacerlo, pasando a señalar sólo el puesto eclesiástico que ostentaba. La razón para tal cambio parece lógico buscarla en la propia actitud del prelado. Así, no parece casual que ya en el momento de reseñar la entrada de Pedro de Castilla en Valladolid se le menciona sólo como obispo de Osma ${ }^{102}$.

Y esa será la tónica desde este momento. Así, cuando se recibió en Valladolid a la reina y la princesa navarras que acudían para celebrar el matrimonio con el príncipe Enrique, se señala cómo en la recepción participó el «obispo de Palencia, don Pero"; y poco después, alrededor de septiembre de 1440, vemos cómo, cuando el rey toma la mula que llevaba el obispo y parte para acudir a prender a un rebelde, de nuevo, se le llama sólo "obispo de Palencia» ${ }^{103}$. Poco antes le presenta en la corte con la misma referencia ${ }^{104}$, y en la última ocasión en que Carrillo se refiere a Pedro de Castilla, cuando participó como negociador en nombre del infante Juan antes de la entrada de los infantes en Medina del Campo en junio de 1441, también aparece como "obispo de Palencia»"

Así, la cronística regia no duda en cambiar la forma de referirse al prelado, en una clara muestra de la distinta visión que desde el bando regio se tenía ahora de Pedro de Castilla. Así, el léxico castigaba al prelado, como una extensión más de la ira regia.

100 CARRILLO DE HUETE, P., Crónica del halconero..., p. 262.

101 Me remito a la opinión de GÓMEZ REDONDO sobre éste autor y su visión de la Monarquía, que queda plasmada en su obra: Historia de la prosa medieval..., II, pp. 2.282 y ss.

102 CARRILLO DE HUETE, P., Crónica del halconero..., p. 282.

103 Ibídem, p. 348.

104 Ibídem, p. 345.

105 Ibídem, p. 411. 
En el resto de la cronística es apreciable también el cambio en la forma de referirse a nuestrro prelado. Para empezar, Barrientos no lo menciona en el conjunto de su redacción (lo que no deja de ser digno de mención, dado que incluso participó en negociaciones con él). La Abreviación del halconero sólo recoge la mención del abandono del bando regio, indicando que tal hecho fue cometido por el «obispo de Osma» ${ }^{106}$. Y la toma de la mula por parte del rey se hizo sobre «el obispo de Palencia»107.

Es digno de mención, en cambio, cómo en las obras cronísticas que podríamos considerar más influidas por una posición política distinta al rey y más cercana a los infantes o Álvaro de Luna dejan de mencionar por completo al prelado. La Crónica de don Álvaro de Luna directamente no le vuelve a mencionar. Así, el silenciamiento pasa a ser el castigo impuesto contra alguien que colaboró con el rival político. Pérez de Guzmán, en el tramo cronístico publicado como la Refundición, tampoco lo menciona. La recopilación de Galíndez, que se basa en este punto en Pérez de Guzmán ${ }^{108}$, tampoco lo menciona más allá de lo que indica Carrillo de Huete y Pérez de Guzmán, salvo el caso de la presencia del prelado junto a la reina en 1441 cuando recibe la aceptación de Álvaro de Luna de la sentencia que le desterraba de la corte ${ }^{109}$, y sus intentos de ser nombrado arzobispo de Toledo en $1442^{110}$. En este sentido, cabe preguntarse el origen de estas dos menciones que no aparecen en la versión conocida de Pérez de Guzmán, tal vez Galíndez pudo cotejar un ejemplar más completo que el que se nos ha conservado. Sea como fuere, lo cierto es que en ambos casos simplemente se indica que era obispo de Palencia.

Así, como vemos, las crónicas marcan una clara diferencia entre este periodo y el precedente a la hora de presentar a Pedro de Castilla. Las menciones a su pertenencia a la familia real desaparecen desde el momento en que desobedece al rey. Incluso, podríamos matizar más el momento: cuando rechaza acudir a la corte con el seguro que le ofrecía el rey con «grand sentimiento». Desde ese momento desaparece toda mención a que fuese nieto del rey Pedro y, con ello, su parentesco con el rey.

La documentación también plasma claramente esta diferencia. El 1 de abril de 1440 parece que sus posibilidades de conseguir beneficios merced a su parentesco con el rey no habían disminuido, al lograr que fuese autorizado para obtener una sede metropolitana, y aún se menciona su condición de descendiente ilegítimo de la progenie regia ${ }^{111}$. Pero posteriormente la situación cambia radicalmente: en la primera mitad de 1441 Juan II escribió al papa informándole de las acciones del prelado que iban en contra de la fidelidad que le debía ${ }^{112}$. Y el pontificado no dudó en actuar pues en julio de 1441 le convocó a Roma para tratar de su desunión con

106 Abreviación..., f. 128v.

107 Ibídem, f. 174v.

108 GÓMEZ REDONDO, F., Historia de la prosa medieval..., II, p. 2264.

109 GALÍNDEZ DE CARVAJAL, L., Crónica de Juan I/ de Castilla..., p. 604.

110 Ibídem, p. 607.

111 A S Vaticano, Reg. Vat., 365, ff. 225r.

112 A S Vaticano, Reg. Vat., 359, f. 131v. El documento carece de fecha, pero parece lógico situarlo en conexión con el que lo contiene de julio de 1441 . 
el rey, indicando que su actuación no era consecuente con el vínculo de consanguinidad que compartían ${ }^{113}$. Como vemos, aún se menciona la relación entre ambos (aunque no sabemos si el rey la manifestaba en sus misivas), pero ahora se utiliza con un matiz distinto, puesto que sirve para recriminarle su actuación.

Así, las menciones a su parentesco con Juan Il o se han desvanecido o se utilizan para recriminar al prelado su actuación contra el monarca. Incluso cuando las fuentes provienen del entorno regio ocurre lo mismo. Así, cuando en junio de 1442 el rey promulga las Ordenanzas del Consejo Real, el prelado aparece mencionado como miembro del mismo, pero sólo como «Pedro de Castilla, obispo de Palençia» ${ }^{114}$. Este alejamiento real y léxico choca con la cercanía que el monarca seguía manifestando hacia su hermana Constanza, a la que apoyaba y a la que seguía llamando "tía»" ${ }^{115}$. De todo ello se infiere que lo que podríamos calificar como alejamiento léxico del prelado se debía a su actuación, y no porque Juan II renegase de un trato familiar con sus parientes lejanos.

El alejamiento del prelado de la vida política fue efectivo, tanto es así, que el prelado tardaría ocho años en volver a ser mencionado en el entorno regio. En concreto, en junio de 1452 Pedro de Castilla aparece mencionado de nuevo como oidor de la Audiencia y miembro del Consejo Real, sin mencionar ningún parentesco con el rey ${ }^{116}$. Esto viene a mostrar una incipiente reconciliación entre ambos.

\section{LAS MENCIONES EN ÉPOCA DE ENRIQUE IV Y LOS REYES CATÓLICOS}

La muerte de Juan II supondría el definitivo alejamiento de Pedro de Castilla de la vida política. El nuevo acercamiento en los últimos años de vida de Juan $\mathrm{II}^{117}$ se interrumpió con su fallecimiento y el ascenso de Enrique IV al trono. Desde ese momento deja de ser mencionado como miembro de la administración regia, y apenas va a haber menciones a él en lo que le restaba de vida que nos lo muestren activo en la política del reino.

Es posible que el prelado intentase en un primer momento no verse completamente alejado. Así, fue de los primeros en acudir ante el nuevo monarca para prestarle su fidelidad ${ }^{118}$. Y en los primeros años del reinado intentó participar de for-

113 Ibídem.

114 Biblioteca Nacional, ms. 13259, ff. 332 y ss

115 RÁBADE OBRADÓ, M. del P., «Religiosidad y memoria política: las constituciones de la capilla de Pedro I en Santo Domingo el Real de Madrid (1464)», En la España Medieval, 26 (2003), pp. 227-261, especialmente pp. 232-235. Así, no sólo aceptaba la fundación de una capilla para Pedro I y su hijo el infante Juan en Santo Domingo el Real de Madrid (con el correspondiente traslado de los restos desde la Puebla de Alcocer y Soria respectivamente), sino que dotó la capilla con 30.000 mrs. situados en las tercias de la villa de Madrid.

${ }_{116}$ A C Palencia, Armario 2, legajo 2, doc. 17. Tal vez la mención de consejero se deba al puesto de oidor.

117 VILLARROEL GONZÁLEZ, O., Las relaciones Monarquía-Iglesia..., p. 508.

118 Crónica anónima de Enrique IV de Castilla, 1454-1474, ed. M. del P. Sánchez Parra, pp. 246-247; DE PALENCIA, A., Crónica de Enrique IV, ed. Paz y Meliá, vol. 1, Madrid, 1904, p. 147. 
ma activa en la política, por medio de su inserción en los pactos y alianzas políticas que estaban comenzando a acordarse entre la nobleza castellana ${ }^{119}$. Su relevancia y peso político, empero, debió ser tan escaso que las crónicas del reinado nunca le mencionan como miembro del bando al que se suscribió ${ }^{120}$. Y no tuvo influencia, puesto que en ningún momento se encuentra a Pedro de Castilla realizando algún tipo de tarea de gobierno durante el reinado de Enrique IV. Finalmente se retiró a Valladolid a vivir con su familia ${ }^{121}$.

Las referencias al prelado continúan la tónica anterior. Siempre es mencionado como obispo de Palencia (sede que ya no abandonó), y no se vuelve a mencionar su parentesco con el rey. Con ello se marca cómo desaparece el vínculo que se había utilizado para alzarlo. Incluso en su muerte, recogida por Diego Enríquez del Castillo, se menciona sólo su rango eclesiástico: «suçedió que el obispo de Palençia, don Pedro de Castilla, subiendo a ver vna lavor que en su casa se hasía, cayó de las escaleras abaxo e murió»122. Alejamiento que no supuso olvido. Enrique IV realizó algunas concesiones al prelado y a sus dos hijos. Así, concedió a Pedro de Castilla cierta cantidad de maravedíes en las rentas de la ciudad de Sevilla $^{123}$. O el caso de Sancho de Castilla, que recibió la villa de Herrera de Valdecañas $^{124}$.

Sólo mucho después se volverá a mencionar el parentesco del prelado con el monarca, y con intenciones bien distintas. Por un lado los descendientes de los Castilla se preocuparon por remarcar ese parentesco para engrandecer sus propios orígenes. Esto lo llevaron a cabo de diversos medios, tanto por la redacción de numerosas obras de tipo genealógico en la que se idealizó la vida del prelado que inició el linaje ${ }^{125}$, como por la recuperación de la memoria del padre y abuelo del prelado por medio de ensalzamiento funerario en el monasterio de Santo Domingo el Real de Madrid, así como por otras formas de presentación simbólica de su ascendencia regia, como los emblemas y escudos ${ }^{126}$.

Alguno de sus descendientes también vería reconocido su parentesco con los monarcas, siguiendo la línea marcada por el prelado y otros miembros del linaje. Así, su hijo Sancho, que sería ayo del príncipe Juan (hijo de los Reyes Ca-

\footnotetext{
119 Biblioteca de la Real Academia de la Historia, Colección Salazar y Castro, 9/823, ff. 220 rv.

120 En concreto se alió con el arzobispo de Toledo, el conde de Haro, el marqués de Santillana y los condes de Benavente y Paredes. VILLARROEL GONZÁLEZ, O., «Pedro de Castilla...», p. 160.

121 Ibídem.

122 ENRÍQUEZ DEL CASTILLO, E., Crónica de Enrique IV, ed. de A. Sánchez Martín, Valladolid, 1994 , p. 178.

${ }_{123}$ CARANDE R., CARRIAZO, y J. de M., El Tumbo de los Reyes Católicos del Concejo de Sevilla, II, Sevilla, 1968, p. 21.

124 Biblioteca de la Real Academia de la Historia, Colección Salanzar y Castro, M-96, ff. 288.r299v.

125 Se pueden encontrar redacciones de las mismas en: Biblioteca de la Real Academia de la Historia, Colección Salazar y Castro, 9/322, ff. 1r-50v; y Biblioteca Nacional de España, ms. 1372, ff. 81v y ss.

126 Véase al respecto: RÁBADE OBRADÓ, M. del P., «Religiosidad y memoria política.... ; y el ya citado GONZÁLEZ DE FAUVE, M.E., LAS HERAS I.J., y DE FORTEZA, P., «Simbología del poder en un linaje castellano...».
} 
tólicos), era reconocido como miembro del linaje real. En época de Enrique IV se conocía el parentesco, y como tal se le presentaba al rey ${ }^{127}$. Isabel I se haría eco al confirmar la donación que Enrique IV le hizo de la villa de Herrera de Valdecañas, mencionando a Sancho como su «pariente ${ }^{128}$.

\section{CONCLUSIONES}

Como se ha podido ver a lo largo del estudio, se puede afirmar que el recuerdo de la pertenencia al linaje real se utilizó como una forma simbólica de ensalzamiento de un personaje de cierto peso político en el siglo XV. El hecho de que Pedro de Castilla sea presentado como descendiente de Pedro I suponía una forma clara de ensalzarle. Esto fue utilizado tanto desde el entorno regio, como desde el pontificio y en particular por la propia familia del prelado. Pero no sólo eso, la evolución del léxico empleado a lo largo de los años muestra claramente cómo se varía la forma de referirse al personaje según su posición política. Así, se puede afirmar que se da una utilización del vocabulario con fines simbólicos y representativos de forma consciente. La forma en la que se refieren al prelado desde el entorno regio o pontificio es una buena muestra de este hecho.

Esta utilización simbólica del léxico es perfectamente apreciable en la variación a lo largo del reinado, según el prelado esté junto al rey u opuesto a él. Si la cercanía a Juan II tiene como recompensa el reconocimiento del parentesco, el alejamiento de su voluntad supone el «destierro» simbólico de ese ámbito. Una vez que el rey muestra el sentimiento que le ha producido el alejamiento de su tío de su línea política, el prelado es presentado como un obispo más del reino, del que se olvida de forma consciente su pertenencia a la familia regia. $Y$ es más significativo si tenemos en cuenta que en esos momentos otros miembros de su familia sí veían reconocido ese parentesco, como es el caso de su hermana Constanza, priora del monasterio de Santo Domingo el Real de Madrid, que veía sus iniciativas de restauración del prestigio de su regio antepasado apoyadas y aceptadas por el monarca, quien marcaba su vínculo familiar. Así, se demuestra claramente la utilización consciente de formas léxicas como medio para ensalzar y legitimar el ascenso al poder de un colaborador regio. Formas que no se aplican sólo por el parentesco sino también por la afinidad, en lo que supone una clara utilización simbólico-política. La Monarquía de Juan II mostraba con ello una continuidad de la línea que al respecto había tenido la reina Catalina, así como el fomento que hacía de personajes fieles al rey.

Sin embargo, esa forma de presentar a Pedro de Castilla, así como la representación clara de su pertenencia al linaje regio, es algo que va a tener importancia más allá de la propia actuación de Juan II. Visto como una forma inmejorable

27 Biblioteca de la Real Academia de la Historia, Colección Salazar y Castro, M-96, f. 291v.

128 Ibídem, f. 289r. No era un noble tan importante como para atribuirle ese apelativo de forma honorífica. 
de situar su estatus por encima de la nobleza que le rodea, la familia del prelado no duda en utilizar las menciones a su ascendencia regia. De hecho, como se sabe, se publica y hace manifiesto, al recuperar la memoria funeraria del rey Pedro I y ensalzar la de su hijo Juan, origen de esa rama de la familia Castilla. Con ello, se estaba produciendo una transferencia de formas simbólicas de tipo léxico de la Monarquía a la nobleza. 